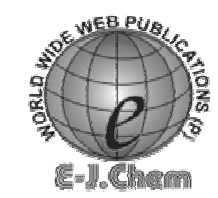

http://www.e-journals.net

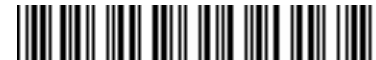

ISSN: 0973-4945; CODEN ECJHAO

E-Journal of Chemistry

Vol. 1, No. 2, pp 132-136, April 2004

\title{
Kinetics of Oxidation of Some Essential Amino Acids by $N$-Chlorosaccharin in Aqueous Acetic Acid Medium
}

\author{
N. A. MOHAMED FAROOK*, G. A. SEYED DAMEEM, \\ A. MURUGESAN and M. KANAGARAJ \\ P. G \& Research Department of Chemistry \\ Khadir Mohideen College, \\ Adirampattinam - 614701 India \\ nafarook@hotmail.com
}

Received 15 March 2004; Accepted 30 March 2004

\begin{abstract}
The kinetics of oxidation of some essential amino acids namely, valine, leucine and phenylalanine, (AA) by $N$-chlorosaccharin (NCSA) in aqueous acetic acid medium in the presence of perchloric acid have been investigated. The observed rate of oxidation is first order in [AA], [NCSA] and of inverse fractional order in $\left[\mathrm{H}^{+}\right]$. The main product of the oxidation is the corresponding aldehyde. The ionic strength on the reaction rate has no significant effect. The effect of changing the dielectric constant of the medium on the rate indicates the reaction to be of dipole-dipole type. Hypochlorous acid has been postulated as the reactive oxidizing species. The reaction constants involved in the mechanism are derived. The activation parameters are computed with respect to slow step of the mechanism.
\end{abstract}

Keywords: Oxidation, Kinetics, Amino acids, $N$-Chlorosaccharin

\section{Introduction}

The chemistry of reactions of $N$-halo compounds form a separate branch, which is a great synthetic importance. ${ }^{1} \mathrm{~N}$-Halo compounds have been extensively employed as oxidizing agents for organic substrates ${ }^{2-3}$. In the recent development, $N$-halo compounds are the source of positive halogen and have been exploited as oxidant for a variety of substrates in both acidic and alkaline media. The nature of active oxidizing species and mechanism 
depends on the nature of the halogen atom, the groups attached to the nitrogen and the reaction conditions. Although a lot of works have been reported on the oxidation of organic compounds by $N$-halo compounds, ${ }^{4-7}$ it is to be noted that no systematic kinetic investigation on the oxidation of amino acids by $\mathrm{N}$-chlorosaccharin has yet been reported in the literature. Here we report the results of the kinetics of the oxidation of valine, 1 eucine and phenylalanine (AA) with $N$-chlorosaccharin (NCSA) in aqueous acetic acid medium in the presence of perchloric acid.

\section{Experimental}

All the chemicals used were of A.R. grade. Double-distilled water was used throughout. $\mathrm{N}$ chlorosaccharin ${ }^{8}$ were prepared using reported procedures. Standard solution of NCSA was prepared afresh. Perchloric acid (AnalaR) was used as source of hydrogen ions. Sodium perchlorate (Merck) was used to keep the ionic strength constant.

The reaction was carried out under pseudo-first order condition ([AA] $>>[\mathrm{NCSA}]$ ). The reaction was followed by potentiometrically by setting up a cell made up of the reaction mixture into which the platinum electrode and reference electrode (SCE) were dipped. The emf of the cell was measured periodically using an Equip-Tronic potentiometer, while the reaction mixture was continuously stirred. The pseudo-first order rate constants computed from the plots of $\log \left(\mathrm{E}_{\mathrm{t}}-\mathrm{E}_{\infty}\right)$ against time were reproducible within $\pm 3 \%$.

\section{Results and Discussion}

Stoichiometry and reaction products

Different sets of reaction mixtures containing different quantities of NCSA and AA at constant concentration of perchloric acid and sodium perchlorate were allowed to react for $24 \mathrm{~h}$ at $30^{\circ} \mathrm{C}$ and then analyzed. The remaining NCSA was estimated. The oxidation products were identified as aldehyde and saccharin by their spot tests; it was confirmed by noting the mixed melting point, chemical methods and TLC techniques. The results are in good agreement with 1:1 stoichiometry.

$$
\begin{aligned}
& \mathrm{RCH}\left(\mathrm{NH}_{2}\right) \mathrm{CO}_{2} \mathrm{H}+\mathrm{C}_{6} \mathrm{H}_{4} \mathrm{SO}_{2} \mathrm{CONCl}+\mathrm{H}_{2} \mathrm{O} \longrightarrow \\
& \mathrm{RCHO}+\mathrm{C}_{6} \mathrm{H}_{4} \mathrm{SO}_{2} \mathrm{CONH}+\mathrm{CO}_{2}+\mathrm{NH}_{3}+\mathrm{HCl} \\
& \text { Where R }=\left(\mathrm{CH}_{3}\right)_{2} \mathrm{CH}, \quad\left(\mathrm{CH}_{3}\right)_{2} \mathrm{CHCH}_{2}, \mathrm{C}_{6} \mathrm{H}_{5} \mathrm{CH}_{2}
\end{aligned}
$$

\section{Reaction order}

The kinetics of oxidation of amino acids by NCSA was investigated at several initial concentrations of the reactants in 50\%-80\% acetic acid-water mixture in the presence of perchloric acid. At constant $\left[\mathrm{H}^{+}\right]$with [substrate] in excess, the plot of $\log \left(\mathrm{E}_{\mathrm{t}}-\mathrm{E}_{\infty}\right)$ versus time is linear, indicating a first order dependence of rate on [NCSA]. Plots of $\log \mathrm{k}_{\mathrm{obs}}$ versus $\log [\mathrm{AA}]$ are linear with a slope of nearly unity for all the substrates (Figure 1) and a plot of $\mathrm{k}_{\mathrm{obs}}$ versus [AA] is also linear passing through the origin indicating a first order dependence on [AA] (Figure 2). The pseudo-first order rate constants decrease with increase in $\left[\mathrm{H}^{+}\right]$in the range $0.5-1.6 \mathrm{~mol} \mathrm{dm}^{-3}$ (Table 1). The linearity of the plots of log [NCSA] versus time indicates the order in [NCSA] as unity. 
The rate increases with increase in dielectric constant of the medium. A plot of log $k_{\text {obs }}$ versus $[D-1 / 2 D+1]$, where $D$ is the dielectric constant of the medium, is linear with positive slope indicating a dipole- dipole type of interation. The reaction have been studied in the temperature range $30-50^{\circ} \mathrm{C}$ and using Arrhenius equation the thermodynamic parameters have been calculated (Table 2). The oxidation of amino acids by NCSA under nitrogen atmosphere fails to induce polymerization of added acrylonitrile, thus ruling out radical oxidation. The retarding effect of added saccharin suggests that the pre-equilibrium step involves hydrolysis of NCSA to give saccharin and $\mathrm{HOCl}$ (eq. 2).

$$
\mathrm{C}_{6} \mathrm{H}_{4} \mathrm{SO}_{2} \mathrm{CONCl}+\mathrm{H}_{2} \mathrm{O} \stackrel{\mathrm{k}_{1}}{\rightleftharpoons} \mathrm{C}_{6} \mathrm{H}_{4} \mathrm{SO}_{2} \mathrm{CONH}+\mathrm{HOCl}
$$

Of the four probable oxidizing species in the reaction, viz. $\mathrm{NCSA}, \mathrm{NCSAH}^{+}, \mathrm{HOCl}$ and $\mathrm{H}_{2} \mathrm{OCl}^{+}, \mathrm{HOCl}$ is considered as the active oxidizing species since the rate is an inverse function of [saccharin] and $\left[\mathrm{H}^{+}\right]$.

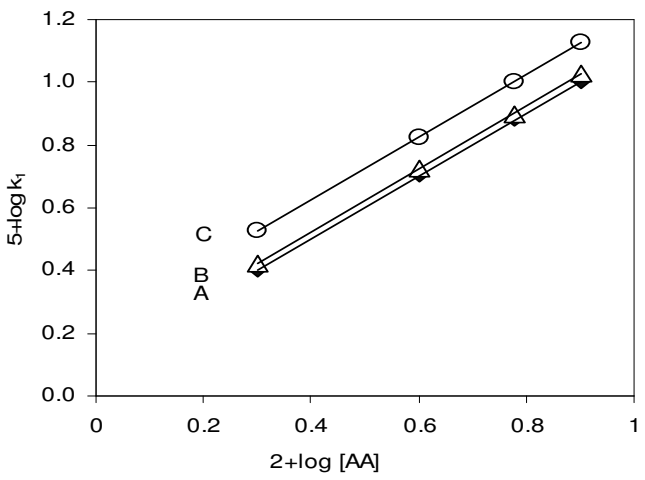

Figure 1. Plots of $\log [\mathrm{AA}]$ versus $\log \mathrm{k}_{1}(\mathrm{~A}=$ Valine $; \mathrm{B}=$ leucine ; $\mathrm{C}=$ Phenylalanine $)$

Table 1. Effect of varying [amino acid], [NCSA] and $\left[\mathrm{H}^{+}\right]$on the rate of reaction at $30^{\circ} \mathrm{C}^{\mathrm{a}}$.

\begin{tabular}{cccccc}
\hline \multirow{2}{*}{$\begin{array}{l}10^{2}[\mathrm{AA}] \\
\mathrm{mol} \mathrm{dim}^{-3}\end{array}$} & \multicolumn{2}{c}{$\begin{array}{c}1^{3}[\mathrm{NCSA}] \\
\mathrm{mol} \mathrm{dm}^{-3}\end{array}$} & \multicolumn{2}{c}{$\left.\mathrm{H}^{+}\right]$} & \multicolumn{3}{c}{$10^{5} \mathrm{X} \mathrm{k}_{\text {obs s }}{ }^{-1}$} \\
\hline 2.0 & 1.0 & 0.5 & 2.52 & 2.64 & 3.36 \\
4.0 & 1.0 & 0.5 & 5.05 & 5.34 & 6.71 \\
6.0 & 1.0 & 0.5 & 7.58 & 7.92 & 10.1 \\
8.0 & 1.0 & 0.5 & 9.99 & 10.6 & 13.4 \\
2.0 & 3.0 & 0.5 & 2.66 & 2.66 & 3.33 \\
2.0 & 5.0 & 0.5 & 2.64 & 2.64 & 3.35 \\
2.0 & 7.0 & 0.5 & 2.63 & 2.63 & 3.34 \\
2.0 & 1.0 & 0.8 & 2.15 & 2.28 & 2.51 \\
2.0 & 1.0 & 1.2 & 1.74 & 1.85 & 2.06 \\
2.0 & 1.0 & 1.6 & 1.31 & 1.42 & 1.78 \\
\hline
\end{tabular}

${ }^{a}$ General conditions: $\left[\mathrm{NaClO}_{4}\right]=0.5 \mathrm{~mol} \mathrm{dm}{ }^{-3}$,

Solvent composition: $50 \%$ Acetic acid - 50\% Water (v/v). 


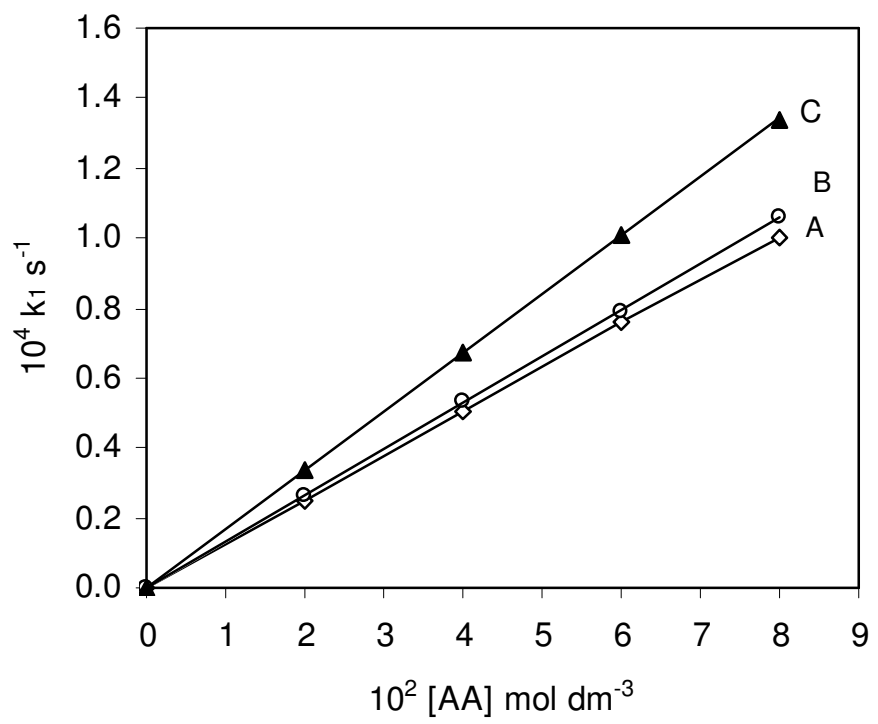

Figure 2. Plots of $[\mathrm{AA}]$ versus $\mathrm{k}_{1}(\mathrm{~A}=$ Valine $; \mathrm{B}=$ Leucine $; \mathrm{C}=$ Phenylalanine $)$

Table 2. Activation parameters for the oxidation of amino acids by NCSA. ${ }^{a}$

\begin{tabular}{cccc}
\hline Parameters & Valine & Leucine & Phenylalanine \\
\hline $\left.10^{5} \mathrm{k}_{\text {obs s }}{ }^{-1}\right)$ & 2.52 & 2.64 & 3.36 \\
$\mathrm{E}_{\mathrm{a}}\left(\mathrm{k} \mathrm{J} \mathrm{mol}^{-1}\right)$ & 45.7 & 47.6 & 49.2 \\
$\Delta \mathrm{H}^{*}\left(\mathrm{k} \mathrm{J} \mathrm{mol}^{-1}\right)$ & 43.2 & 45.1 & 46.7 \\
$\Delta \mathrm{S}^{*}\left(\mathrm{JK}^{-1} \mathrm{~mol}^{-1}\right)$ & 40.2 & 41.2 & 43.2 \\
$\Delta \mathrm{G}^{*}\left(\mathrm{k} \mathrm{J} \mathrm{mol}^{-1}\right)$ & 61.2 & 65.2 & 72.4 \\
\hline
\end{tabular}

${ }^{a}$ General conditions: $\left[\mathrm{NaClO}_{4}\right]=0.5 \mathrm{~mol} \mathrm{dm}{ }^{-3}$,

Solvent composition: $50 \%$ Acetic acid - 50\% Water $(\mathrm{v} / \mathrm{v})$

$[A A]=0.02 \mathrm{~mol} \mathrm{dm}^{-3},[N C S A]=0.001 \mathrm{~mol} \mathrm{dm}^{-3}$.

The retarding effect of $\left[\mathrm{H}^{+}\right]$on the rate of reaction can be explained by considering the equilibrium (3) between the substrate (AA) and $\mathrm{H}^{+}$.

$$
\mathrm{S}+\mathrm{H}^{+} \stackrel{\mathrm{k}_{2}}{=} \mathrm{SH}^{+}
$$

This effect coupled with the solvent effect does point out that the reaction with unprotonated amino acid should be more predominant.

\section{Mechanism}

The first order dependence each on [AA] and [NCSA] reveals that overall rate may involve the interaction of $\mathrm{HOCl}$ and amino acid in the rate determining step to give a mono ester similar to that reported by Komal Reddy and Sundaram for $N$-bromoacetamide oxidations $^{9,10}$. The mono ester involving $O-\mathrm{Cl}$ linkage may then undergo a series of fast steps as shown in Scheme 1 to give aldehyde and ammonia. 


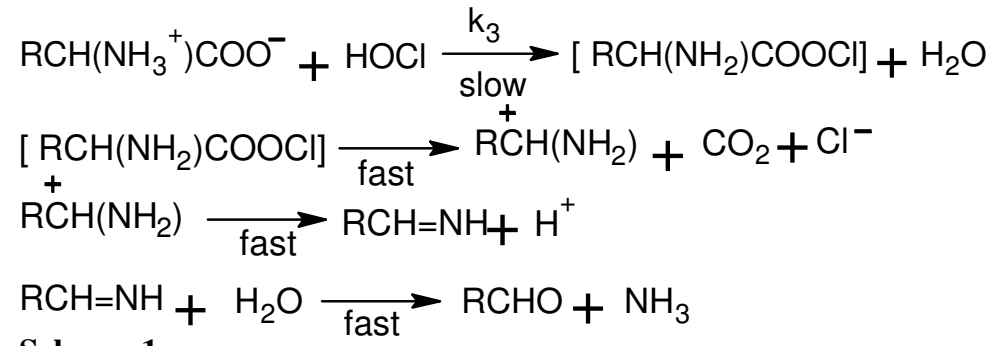

\section{Scheme 1}

The rate law based on scheme 1 is represented by eq. (8)

$$
\frac{-\mathrm{d}[\mathrm{NCSA}]}{\mathrm{dt}}=\frac{\mathrm{k}_{1} \mathrm{k}_{3}[\mathrm{NCSA}]\left[\mathrm{SH}^{+}\right]}{\mathrm{k}_{2}\left[\mathrm{H}^{+}\right]\left[\mathrm{C}_{6} \mathrm{H}_{4} \mathrm{SO}_{2} \mathrm{CONH}\right]}
$$

Equation (8) clearly points out the observed results, i.e. first order in [NCSA], [AA] and inverse first order in $\left[\mathrm{H}^{+}\right]$negligible influence of changes in ionic strength and the effect of dielectric constant of the medium on the rate of oxidation.

\section{Acknowledgment}

The author N.A.Mohamed Farook is thankful to UGC for financial support to complete this project

\section{References}

1. (a) Patrocino F A J Organomet. Chem. 2000603220 (b) Dhurn P S, Mohe N U and Salunkhe M M Synth. Commun. 2001313653 (c) Caribano V, Rodriguez J F, Santose M, Sanz-Tejedor M A, Carreno M C, Gonzalez G and Garcia-Ruano J L Synthesis 2001142175 (d) Bandgar B P, Uppalla L S and Sadavarte V S Syn. Lett. 2001111715

2. Thenraja D, Subramaniam P and Srinivasan C J. Chem. Soc. Perkin Trans 20022 2125

3. Mukaiyama T, Mastsuo J I, Lida D and Kitagawa H Chem. Lett. 20018846

4. Hambly G F and Chan T H Tetrahedron Lett. 1986272563

5. Antelo J M, Arce F, Crugeiras J O and Parajo M J. Phys. Org. Chem. 199710631

6. Karunakaran C and Ganapathy K Indian J. Chem. 1990 29A 133

7. Harihar A L, Kembhavi M R and Nandibewoor S T J. Indian Chem. Soc. 199976128

8. Chattaway F D J. Chem. Soc. 1905871884

9. Komal Reddy M and Sundaram E V Indian J. Chem. 1986 25A 471

10. Gopalakrishnan G and Hogg J L J. Org. Chem. 1985501206 


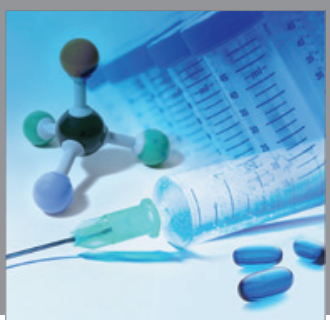

International Journal of

Medicinal Chemistry

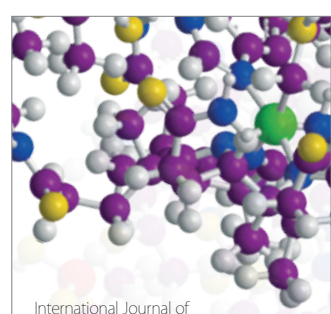

Carbohydrate Chemistry

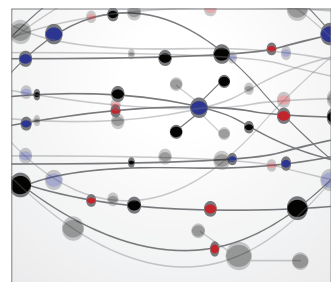

The Scientific World Journal
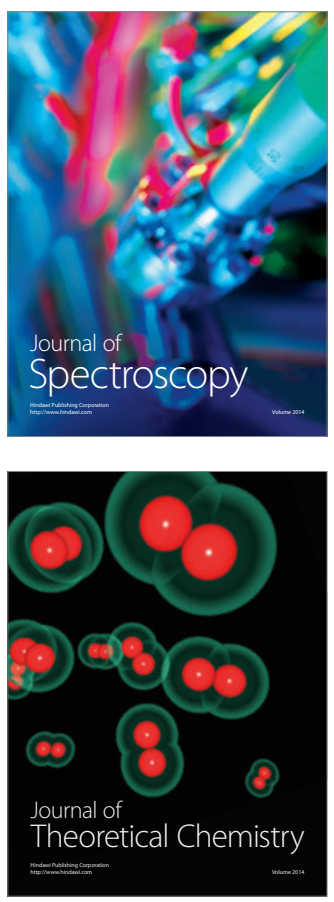
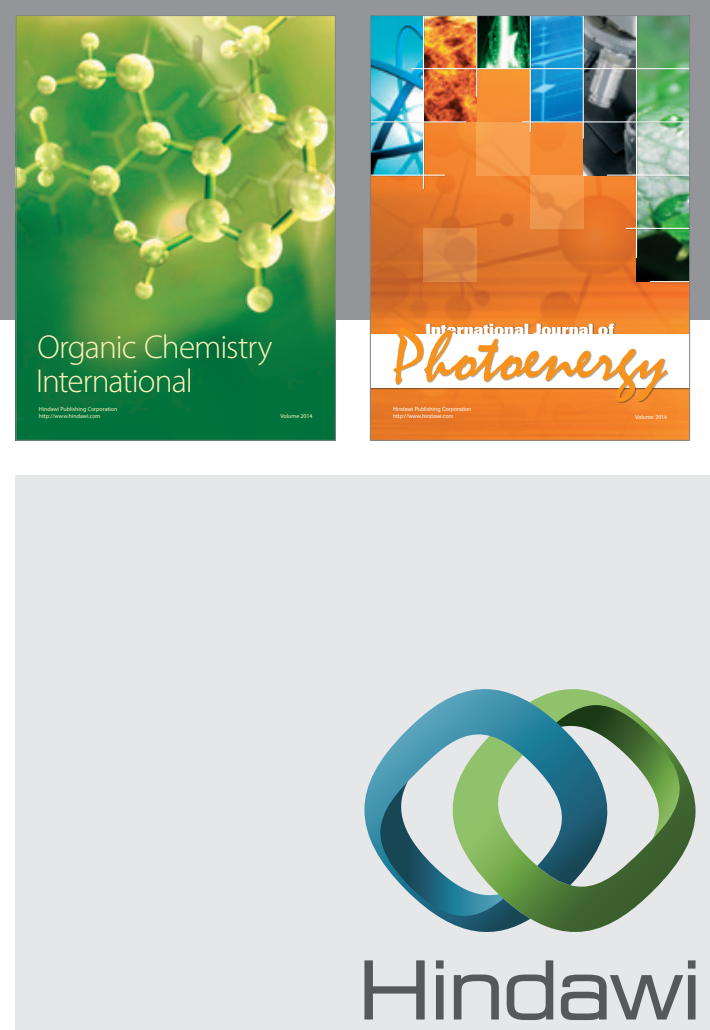

Submit your manuscripts at

http://www.hindawi.com
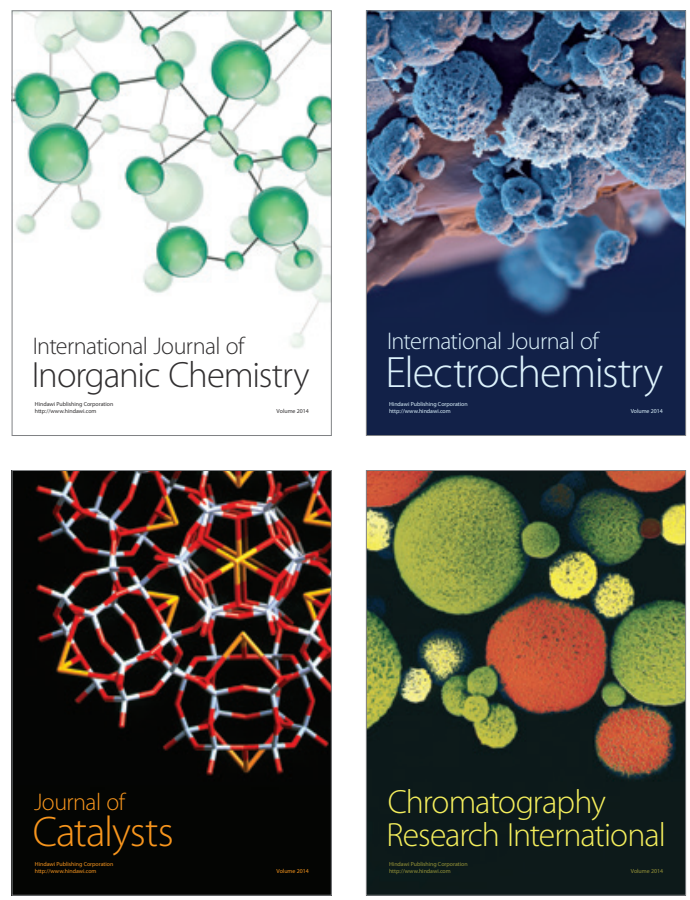
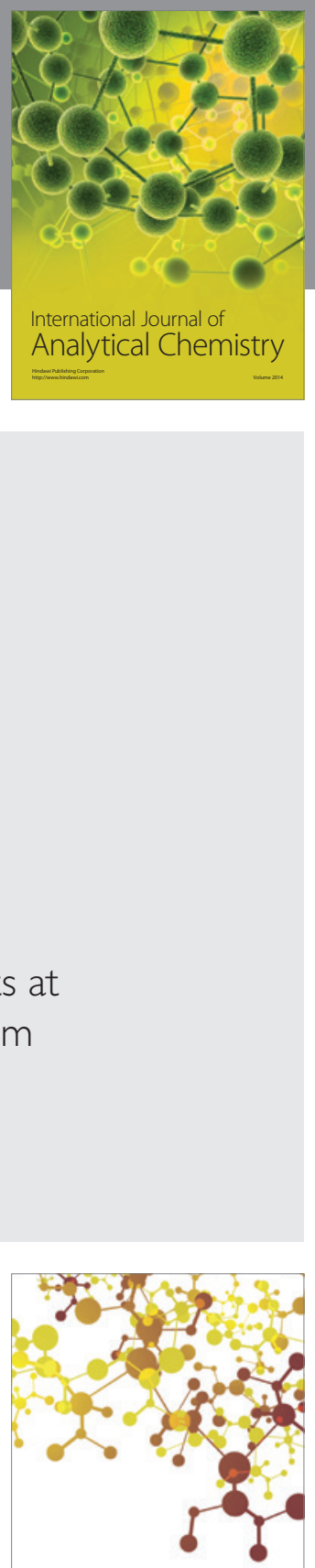

Journal of

Applied Chemistry
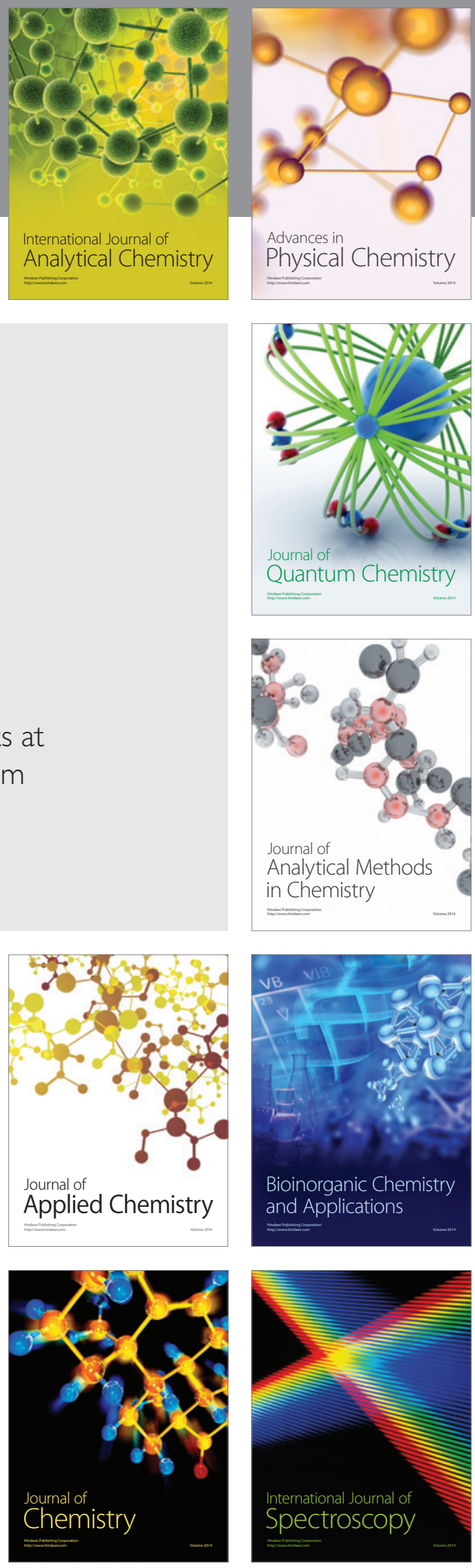